be taken of the possibility of the presence of dimers and higher order clusters at higher concentrations. ${ }^{17}$

This work was supported by the Advanced Research Projects Agency through the Center for Materials Research at Stanford University. The authors sincerely appreciate the assistance of A. D. Franklin for providing the samples used in this work. The valuable help of M. S. Whittingham is also gratefully acknowledged.

1 E. Friedman and W. Low, J. Chem. Phys. 33, 1275 (1960). $2 \mathrm{~J}$. Sierro and R. LaCroix, Compt. Rend. 250, 2686 (1960).

${ }^{3}$ T. Rewaj, Fiz. Tverd. Tela 10, 1272 (1968) [Solid State 10, 1014 (1968)].

${ }^{4}$ A. D. Franklin and S. Marzullo, Proc. Brit. Ceram. Soc. 19, 135 (1970)

${ }^{5} \mathrm{~J}$. Makovsky, Physics of Quantum Electronics (McGrawHill, New York, 1966), p. 340.

${ }^{6}$ E. Loh, Phys. Rev. 154, 270 (1967).

7 I. G. Saitkulov and A. Stolov, Fiz. Tverd. Tela 10, 2163 (1968) [Solid State 10, 1694 (1969)].
${ }^{8}$ F. K. Fong and M. A. Hiller, J. Phys. Chem. 71, 2854 (1967). ${ }^{2}$ B. S. H. Royce and S. Mascarenhas, Phys. Rev. Letters 24, $98(1970)$.

${ }_{10}$ This technique was termed the method of ionic thermocurrents (ITC) by its originators. However, we believe the label used here to be more descriptive of the actual phenomenon observed. [C. Bucci and R. Fieschi, Phys. Rev. Letters 12, 16 (1964).]

${ }_{11}$ R. D. Shelley and G. R. Miller, J. Solid State Chem. 1, 218 (1970)

${ }_{12}$ D. R. Stiefbold, Ph.D. dissertation, Stanford University, 1971

${ }^{13}$ D. R. Stiefbold and R. A. Huggins, "Dipole Reorientation Kinetics in Rare Earth-Doped $\mathrm{CaF}_{2}$," J. Solid State Chem. (to be published).

${ }_{14} \mathrm{~J}$. P. Stott and J. H. Crawford, Jr., Phys. Rev. Letters 26, 384 (1971).

15 J. P. Stott and J. H. Crawford, Jr., Phys. Rev. Letters "Reorientation of Impurity-Fluoride Interstitial Complexes in Rare Earth-Doped CaF," (to be published).

${ }^{16}$ F. Lüty, J. Phys. (Paris) 28, C4-120 (1967).

${ }^{17}$ F. K. Fong, R. L. Ford, and R. H. Heist, Phys. Rev. B 2, $4202(1970)$.

\title{
CNDO Calculation of Side Chain-Main Chain Angular Dependence in Paraffin and Peptide Chains
}

\author{
E. W. RONISH AND S. KRIMM \\ Harrison M. Randall Laboratory of Physics and Macromolecular Research Center, University of Michigan, Ann Arbor, Michigan 48104
} (Received 29 November 1971)

It is often difficult to determine experimentally the location of side chain atoms with respect to the main chain in a polymer molecule, especially if one or both of the side chain atoms is hydrogen. A relation which gives side chain positions as a function of main chain geometry would therefore be useful in structural studies and in conformational energy calculations, for example, on biopolymers. An attempt has been made to do this ${ }^{1}$ by means of an approximate calculation of the constant $b$ in $\Delta \beta=-b \Delta \alpha$, where $\beta$ is $\angle \mathrm{XC}_{2} \mathrm{Y}$ and $\alpha$ is $\angle \mathrm{C}_{1} \mathrm{C}_{2} \mathrm{C}_{3}$ in the structure $\mathrm{C}_{1}-\mathrm{C}_{2}(\mathrm{XY})-\mathrm{C}_{3}$. It was found that $b \cong 0.30$ for $\mathrm{X}=\mathrm{Y}=\mathrm{H}, b \cong 0.23$ for $\mathrm{X}=\mathrm{C}$ and $\mathrm{Y}=\mathrm{H}$, and $b \cong 0.20$ for $\mathrm{X}=\mathrm{Y}=\mathrm{C}$. We have determined $b$ by a CNDO calculation, both for paraffin type molecules as well as for a peptide chain, and find results differing from the above.

The CNDO program which we used ${ }^{2}$ calculates the total energy of the molecule within the framework of an SCF calculation. The molecular orbitals are fitted into a Slater determinant. This choice of wavefunction causes correlation energies to be neglected but still maintains the correct symmetry of the exact solution of the Hamiltonian. An accurate SCF wavefunction should therefore give the correct angular relationships in a molecule. ${ }^{3}$ The CNDO method has many approximations in it, but it still maintains the basic properties of an SCF calculation and seems to give good angular determinations in a molecule. ${ }^{2}$

The first molecule calculated was propane, $\mathrm{CH}_{3-}$ $\mathrm{CH}_{2} \mathrm{CH}_{3}$. Experimental bond lengths ${ }^{4}$ were used. The central $\mathrm{HCH}$ angle $(\beta)$ was varied for each value of the CCC angle angle $(\alpha)$, the methyl hydrogens being kept fixed in their equilibrium positions. The total energy was calculated at each value of $\beta$, and the minimum energy was determined graphically. The points obtained for a series of values of $\alpha$ gave a very good least squares straight line with a slope given by $\Delta \beta / \Delta \alpha=$ -0.13 , which is less than half of that predicted previously. ${ }^{1}$ Considerable credence was lent to this calculation by noting that the absolute energy minimum occurred at $\angle \mathrm{CCC}=112.2^{\circ} \pm 0.5^{\circ}, \angle \mathrm{HCH}=106.2^{\circ} \pm$ $0.5^{\circ}$, and $\angle \mathrm{CCH}$ (methyl) $=111.1^{\circ} \pm 1.0^{\circ}$, which compares very well with the experimentally determined values of $112.4^{\circ} \pm 0.2^{\circ}, 106.1^{\circ} \pm 0.2^{\circ}$, and $111.8^{\circ} \pm 1.0^{\circ}$, respectively. ${ }^{4}$

Next a CNDO calculation was done for $N$-acetylalanine- $N$-methylamide, $\mathrm{CH}_{3}-\mathrm{NH}-\mathrm{C}^{\prime} \mathrm{O}-\mathrm{C}_{\alpha} \mathrm{H}_{\alpha}\left(\mathrm{C}_{\beta} \mathrm{H}_{3}\right)-$ $\mathrm{NH}-\mathrm{C}^{\prime} \mathrm{O}-\mathrm{CH}_{3}$, which should serve as a model for polypeptides and proteins. The following geometry was used: $l\left(\mathrm{C}_{\alpha}-\mathrm{C}^{\prime}\right)=1.53 \AA, l\left(\mathrm{C}^{\prime}-\mathrm{O}\right)=1.24 \AA, l\left(\mathrm{C}^{\prime}-\mathrm{N}\right)=$ $1.32 \AA, l(\mathrm{~N}-\mathrm{H})=1.00 \AA, l\left(\mathrm{~N}-\mathrm{C}_{\alpha}\right)=1.47 \AA, l\left(\mathrm{C}-\mathrm{H}_{3}\right)=$ $1.09 \AA, \angle \mathrm{C}_{\alpha} \mathrm{C}^{\prime} \mathrm{N}=114^{\circ}, \angle \mathrm{C}_{\alpha} \mathrm{C}^{\prime} \mathrm{O}=121^{\circ}, \angle \mathrm{C}^{\prime} \mathrm{NH}=$ 


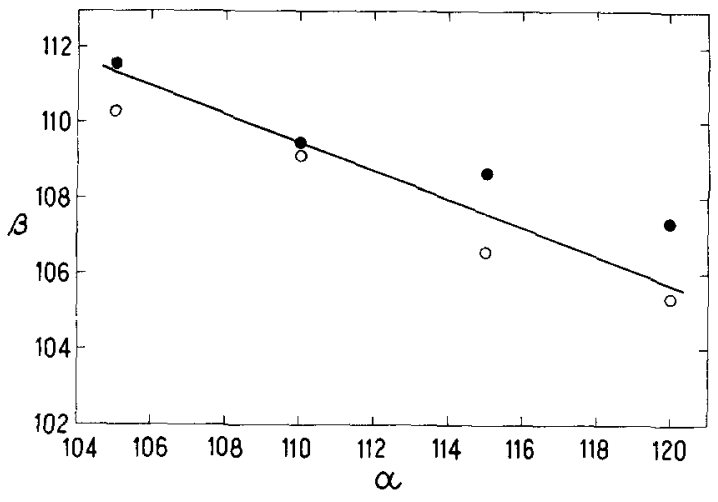

Fig. 1. Variation of side chain angle $\beta=\angle \mathrm{C}_{\beta} \mathrm{C}_{\alpha} \mathrm{H}_{\alpha}$ with main chain angle $\alpha=\angle \mathrm{C}^{\prime} \mathrm{C}_{\alpha} \mathrm{N}$ in $N$-acetylalanine- $N$-methylamide, $\mathrm{CH}_{3}-\mathrm{NH}-\mathrm{C}^{\prime} \mathrm{O}-\mathrm{C}_{\alpha} \mathrm{H}_{\alpha}\left(\mathrm{C}_{\beta} \mathrm{H}_{3}\right)-\mathrm{NH}-\mathrm{C}^{\prime} \mathrm{O}-\mathrm{CH}_{3}$. O: extended conformation, $\mathrm{O}: \alpha$-helical conformation.

$123^{\circ}, \angle \mathrm{C}^{\prime} \mathrm{NC}_{\alpha}=123^{\circ}$. Again the energy was minimized with respect to the side chain angle $\beta, \angle \mathrm{C}_{\beta} \mathrm{C}_{\alpha} \mathrm{H}_{\alpha}$, at each value of the main chain angle $\alpha, \angle C^{\prime} C_{\alpha} N$. However, in order to check the dependence of such a relation on local conformation, the calculation was done for an extended molecule, viz., $\varphi\left(\mathrm{N}-\mathrm{C}_{\alpha}\right)=-180^{\circ}$ and $\psi\left(\mathrm{C}_{\alpha}-\mathrm{C}^{\prime}\right)=-180^{\circ}$, as well as for a conformation representative of the $\alpha$-helix, viz., $\varphi=-47^{\circ}$ and $\psi=-57^{\circ}$. In the former calculation the positions of $\mathrm{C}_{\beta}$ and $\mathrm{H}_{\alpha}$ were varied independently. Within the accuracy of the calculation the energy was found to minimize with these atoms located symmetrically with respect to the $\mathrm{C}^{\prime} \mathrm{C}_{\alpha} \mathrm{N}$ plane, and this configuration was also used in the latter calculation. The minimum energy orientations of the three methyl groups were also determined for the extended structure, and these were assumed to be the same for the $\alpha$-helical type of structure.

The minimum energy structures are given in Fig. 1. The differences between the extended and $\alpha$-helical structures represent very small energies, and a single least squares line is felt to reasonably represent both. The global minimum energy structure corresponds to $\alpha=110.0^{\circ}$ with $\beta=109.5^{\circ}$ for the extended form and $\beta=109.1^{\circ}$ for the $\alpha$-helical form. The relationship between the changes in these two angles is best represented by $\Delta \beta=-0.37 \Delta \alpha$. This again differs from what would have been suggested by the earlier calculation, ${ }^{1}$ at least if the peptide structure is assumed to correspond most closely to the $\mathrm{X}=\mathrm{C}, \mathrm{Y}=\mathrm{H}$ case.

This research was supported by a Macromolecular Research Center fellowship to one of us (E.W.R.) and by National Science Foundation grant GB-15682.

${ }^{1}$ J. B. Hendrickson, J. Amer. Chem. Soc. 83, 4537 (1961).

$2 \mathrm{~J}$. A. Pople and D. L. Beveridge, Approximate Molecular Orbital Theory (McGraw-Hill, New York, 1970).

${ }^{3}$ O. Sinanoğlu, Advan. Chem. Phys. 6, 315 (1964).

${ }^{4}$ D. R. Lide, J. Chem. Phys. 33, 1514 (1960).

\title{
Analytical Self-Consistent-Field Energy Expression for Ground-State $\mathrm{H}_{3}+$ Ion
}

\author{
Jan-Tsyu J. Huang \\ Department of Chemistry and the Radiation Laboratory, ${ }^{*}$ University of Notre Dame, Notre Dame, Indiana 46556
}

(Received 28 October 1971)

Recently there has been increasing interest in the adoption of the generalized molecules-in-molecules concept to various $\mathrm{MO}$ formalisms. ${ }^{1-3} \mathrm{Ab}$ initio calculations on large molecules using floating spherical Gaussian orbitals of molecular fragments have been carried out by Christoffersen and co-workers, ${ }^{1}$ while a theory of molecules-in-molecules for an approximation to SCF-MO scheme has just been published by von Niessen $^{2}$ and a multiconfiguration SCF theory with distorted atomic orbitals reported by Gilbert. ${ }^{3}$ On the other hand, in the VB approach semiempirical calculations have long been performed following the central idea of molecules-in-molecules, most notably the method of "atoms-in-molecules" by Moffitt" and its extension to "diatomics-in-molecules" (DIM) by Ellison. ${ }^{5}$

Ellison's DIM-VB method has been shown ${ }^{6-8}$ to give simple energy expressions for univalent $\mathrm{A}_{2} \mathrm{~B},{ }^{6}$ $\mathrm{A}_{2} \mathrm{~B}_{2},{ }^{7}$ and $\mathrm{M}_{3}{ }^{+8}$ systems. It would be desirable and worthwhile to examine if there are corresponding SCF energy equations expressible in terms of one-body energies and two-body potentials. As an initial step toward this aim, we wish to present here a case study of the simplest triatomic system, $\mathrm{H}_{3}+$ ion.

An approximate energy expression for the groundstate equilateral $\left(D_{3 h}\right) \mathrm{H}_{3}{ }^{+}$was found in a previous Note $^{8}$ to take the form of diatomics-in-molecules

$$
E_{1}{ }^{\mathrm{H}^{3}+}(R) \simeq E_{1}{ }^{\mathrm{I}_{2}}(R)+2 E_{1}{ }^{\mathrm{H}_{2}+}(R)-2 E_{\mathrm{H}},
$$

where $E_{1} \mathrm{H}_{2}(R)$ is the ground-state energy of $\mathrm{H}_{2}$ at a fixed nuclear distance $R$ and $E_{1}{ }^{\mathrm{H}_{2+}}(R)$ that of groundstate $\mathrm{H}_{2}{ }^{+}$also at $R . E_{\mathrm{H}}$ is the ground-state energy of hydrogen atom, -0.5 a.u. Since the $\mathrm{H}_{3}{ }^{+}$correlation energy is essentially the same as that of $\mathrm{H}_{2},{ }^{9}$ an ap- 